\title{
LEMONGRASS AND CINNAMON ESSENTIAL OILS AS VITAMIN C PRESERVATIVES AND FLAVOUR ENHANCERS IN JAM
}

\author{
Denice Byarushengo, Rwaichi Minja and Abraham Temu \\ Chemical and Mining Engineering Department, University of Dar es \\ Salaam, \\ P.O. Box 35131 Dar es Salaam, Tanzania. \\ Email: m_byarushengo@yahoo.com, Phone: +255 712043082
}

\begin{abstract}
Lemongrass and cinnamon essential oils (LEO and CEO) are natural oils with high antioxidation capacity, pleasant flavour, and various health benefits. Their ability to preserve vitamin $C$ and flavour in jam have not been tested. In this study the performance of two essential oils (EOS) in preserving vitamin $C$ and improving jam flavour were investigated. The EOs were produced by hydro-steam distillation of fresh lemongrasses and cinnamon leaves using a Clevenger apparatus. Jam samples were dosed with various concentrations of either single or mixed EOs and then stored at either room or refrigeration temperature. Samples were analysed for changes in vitamin C content and flavour, after every 10 days for 60 days. Vitamin C content was determined using 2,6 dichlorophenol indophenol visual titration method, whereas sensory analysis was done by five semi trained panellists. It was revealed that both $L E O$ and $C E O$ have high potential to reduce loss of vitamin $C$ and impart better flavour in pineapple jam. The improved quality of the jam is due to antimicrobial and anti-oxidant effects of the essential oils as reported in literature. Mixing the EOs had synergistic effect which maximizes their potential to reduce vitamin C loss with lower dose than when used individually. Mixed EOs doses also enhanced the jam flavour.
\end{abstract}

Keywords: Jam, Essential oil, Lemongrass, Cinnamon

\section{INTRODUCTION}

Retention of vitamin $\mathrm{C}$ is often used as an estimate for the overall nutrient retention of food products because it is by far the least stable nutrient; it is highly sensitive to oxidation and leaching into watersoluble media during storage (Davey etal., 2000; Franke et al., 2004).

Vitamin $\mathrm{C}$ degradation is often responsible for important quality changes that occur during the storage of foods, limiting their shelf-life (Zheng and Lu, 2011). Vitamin $C$ is thermolabile and therefore in fruits it provides an indication of the loss of other vitamins and acts as a valid criterion for other organoleptic or nutritional components such as natural pigments and aromatic substances (Esteve and Frígola, 2007).
The storage environment affects vitamin C content significantly. Many chemical reactions contribute to the loss of storage life of vitamin $\mathrm{C}$ and hence chemical deterioration of fruits. The majority of these reactions are enzymatically driven while others are chemical reactions that occur because of the aging processes. However, oxygen is the most destructive ingredient in causing degradation of vitamin C (Ajibola et al., 2009).

Changes in flavour are the most sensitive index to quality deterioration during storage followed by colour (Eckerle etal., 1984). For a very long time, spices and herbs have been added to foods, the main purpose being to change or improve taste/flavour of the foods. It is well known that the volatile constituents of the plants 
are the ones responsible for aroma, taste and even for the antimicrobial nature of the plants (Rasooli, 2007). These can be isolated in form of liquid referred to as essential oils (EOs).

Many EOs have been reported to have radical-scavenging ability and thus to reduce oxidation which can cause oxidative deterioration including loss of vitamin $\mathrm{C}$ and off flavour development in foods (Özcan and Arslan, 2011; Sacchetti et al., 2005; Singh et al., 2007).

Combinations of EOs can work synergistically and more effective than single essential oils (Bailey, 2010). This can be exploited to maximize activity of EOs thereby minimizing the concentrations required to achieve a particular preservation effect. This in turn will minimize the effect of EOs on sensory properties of foods. However, this has not been investigated in jam. This study aimed at investigating performance of the mixed EOs in preserving vitamin $\mathrm{C}$ and improving flavour of jam.

\section{MATERIAL AND METHODS}

\subsection{Extraction of Essential Oils}

Fresh Cymbopogon citrates (lemongrass) and Cinnamomum (cinnamon) leaves were obtained from traders in Dar es Salaam region and Zanzibar respectively. EOs were extracted by steam and water distillation of clean and fresh leaves using a distillation unit and a Clevenger apparatus (apparatus which separates EOs from water) as shown in Figure 1.

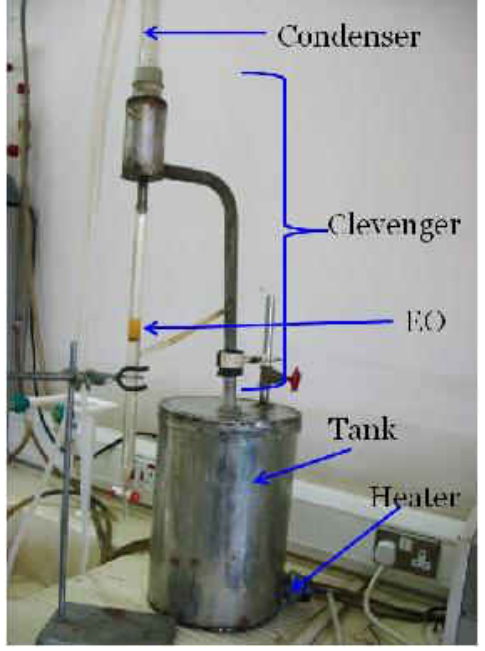

Figure 1: Essential Oil steam distillation with clavenger for oil separation.

\subsection{Preparation of jam ingredients}

With lemon peel extract as a source of pectin, and lemon juice as a source of acid, the green peel of the lemon fruits was first removed. The remaining white peel was removed and extracted by boiling one part with two parts of water (volume by volume) for $30 \mathrm{~min}$. The peeled lemon fruits were squeezed using a kitchen machine to extract the juice.

After preparation of the lemon peels extract and the lemon juice, pineapple fruits were washed with enough, running tap water and then they were peeled, stems removed and then cut into small pieces using sharp stainless steel knives. The sliced pineapples were blended using a kitchen blender. $3.8 \mathrm{~kg}$ (4 Litres) of blended pineapple were put in a clean pot and boiled for about eight minutes. Then, $100 \mathrm{~mL}$ of the pectin extract was added to each litre of the fruit pulp. $3.8 \mathrm{~kg}$ of white sugar was dissolved in $600 \mathrm{~mL}$ of hot water and the sugar solution was added to the grated pineapple.

\subsection{Boiling of jam ingredients}

The mixture was boiled on open, with continuous stirring using wooden spoon until the Brix (measured using Atago Pocket 3840 digital refractometer) had 
reached $65 \% \mathrm{w} / \mathrm{w}$. Then $\mathrm{pH}$ of jam was measured using a pH-meter (ModelThermo Scientific Orion 3 Star $\mathrm{pH}$ Benchtop) and recorded as 4.3. Lemon juice was added in small amounts, with vigorous stirring until the $\mathrm{jam} \mathrm{pH}$ had reached 3.5 which is common for jams (Eke-Ejiofor and Owuno, 2013) and the boiling process was stopped.

\subsection{Addition of EOs and packaging of jam}

Various portions of $840 \mathrm{~mL}$ of jam were packed in plastic bottles. Appropriate volumes of essential oils were added to various portions as required followed by vigorous shaking to ensure that the EOs mixed well with the jam. Nothing was added to one portion (control). For each of the above portions 28 sample bottles were filled up to $30 \mathrm{~mL}$ mark, capped properly. Labelling of samples was done using letters and numbers as elaborated below:

1: $1000 \mathrm{ppm}$ of EO used; 2: $500 \mathrm{ppm}$ of each EO used; 3: $250 \mathrm{ppm}$ of each EO used; N: No Preservatives (EOs); L: Lemongrass EO; C: Cinnamon EO; M: Mixture of lemongrass and cinnamon EOs; R: Stored at room temperature; 4: Stored in refrigerator.

\subsection{Storage of jam samples}

Half of the samples were stored in fridge (at $3.8-4.4^{\circ} \mathrm{C}$ ) while the other samples were stored at room temperature (28$31{ }^{\circ} \mathrm{C}$ ). The storage temperature was constantly recorded by type CEM DT-172 temperature and humidity data logger. Figure 2 summarises the jam preparation process.

\subsection{Evaluation of Performance of Essential Oils on Vitamin C Preservation}

Remaining ascorbic (vitamin C) acid was determined. This was done using 2,6dichlorophenol-indophenol titration method.

\subsection{Standardization of pure ascorbic acid}

Before the quantity of ascorbic acid in the samples was calculated, the $0.025 \% 2,6$ dichlorophenol-indophenol reagent was standardized using $5 \mathrm{mg}$ of pure $(\mathrm{L}+)$ ascorbic acid dissolved in $100 \mathrm{ml}$ of $5 \%$ metephosphoric acid. $10 \mathrm{ml}$ ascorbic acid solution was pipetted into $100 \mathrm{ml}$ conical flask and titrated against the indophenols reagent filled in a burette, until a persistent pink end point was reached.

From the titre volume the quantity of ascorbic acid (in $\mathrm{mg}$ ) reacting with $1 \mathrm{ml}$ of the indophenol reagent was calculated.

\subsection{Extraction of solution for jam samples}

For each sample $5 \mathrm{~g}$ were transferred to $100 \mathrm{ml}$ conical flask, followed by addition of $25 \mathrm{ml}$ of freshly prepared solution of 5\% meta-phosphoric acid (a deproteinizing agent and an ascorbic acid stabilizer). The contents were mixed on a shaker and then left to settle. $10 \mathrm{ml}$ of the solution were decanted from each sample and pipetted into $100 \mathrm{ml}$ conical flask.

\subsection{Determination of ascorbic acid in samples}

For jam, $10 \mathrm{ml}$ was taken from the extracted solution of each sample and pipetted into $100 \mathrm{ml}$ conical flask, then 9 $\mathrm{ml}$ of freshly prepared solution of 5\% meta phosphoric acid was added. Then titration was done two times for all the prepared solutions against the indophenol reagent filled in a burette, until a persistent pink end point was reached. The average volume of the indophenol reagent used for each titration was then used to calculate the quantity in $(\mathrm{mg})$ of ascorbic acid reacting with the indophenol reagent.

\subsection{Calculation of ascorbic acid}

The ascorbic acid content of all jam samples was calculated in $\mathrm{mg} / 100 \mathrm{~g}$ dry weight. The quantity of ascorbic acid (mg) was calculated according to Eq. 1. 


$$
A A=\frac{v_{s 2} \times C_{s t d} \times V_{e s n}}{V_{2} \times W_{s 2}} \times 100
$$

Where: $\mathrm{AA}=$ content of ascorbic acid $(\mathrm{mg} / 100 \mathrm{~g}) ; \quad \mathrm{V}_{\mathrm{sa}}=$ volume $\quad(\mathrm{ml}) \quad$ of indophenol solution required for the complete titration with the sample; $\mathrm{C}_{\text {std }}=$ quantity of standard ascorbic acid (mg) reacting with $1 \mathrm{ml}$ of indophenol reagent; $V_{\text {exn }}=$ total volume of extract, here it was $25 \mathrm{ml} ; \mathrm{V}_{\mathrm{a}}=$ volume of extract used for each titration, here it was $10 \mathrm{ml}$; and $\mathrm{W}_{\mathrm{sa}}=$ weight of sample $(\mathrm{g})$, here it was $5 \mathrm{~g}$.

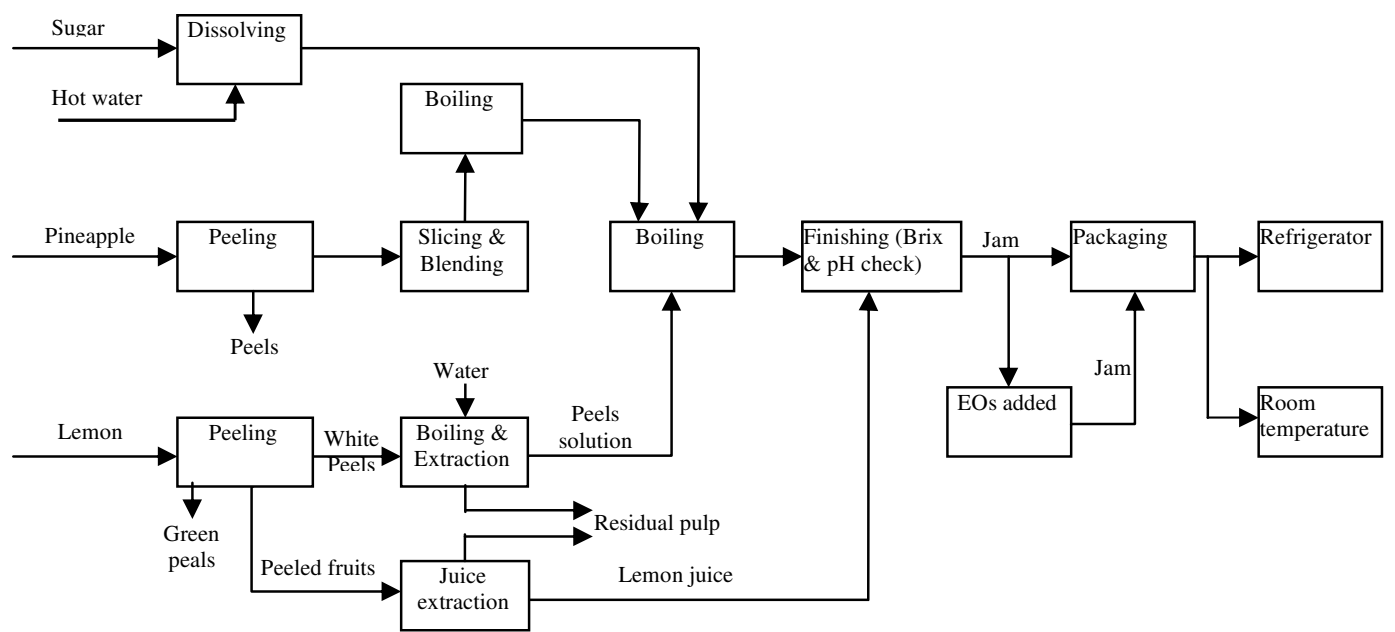

Figure 2: Process for preparation of pineapple jam

\section{RESULTS AND DISCUSSION}

\subsection{Effect of Mixed Essential Oils (MEO) on Vitamin C Loss in Pineapple Jam}

Figures 3 - 6 show that vitamin $\mathrm{C}$ content for both refrigerated and non-refrigerated samples decreased with increasing storage time. Similar results were obtained by (Vidhya and Narain, 2011).

\subsection{Evaluation of Performance of Essential Oils on Jam Flavour}

A panel of five semi trained end-users was used for flavour evaluation during storage of samples. Each day of analysis, randomly selected, but coded samples of all categories were taken from the storage places, tempered to ambient temperature (for samples from the refrigerator) and then evaluated for flavour. The panellists were required to taste one sample at a time, and record their responses. 


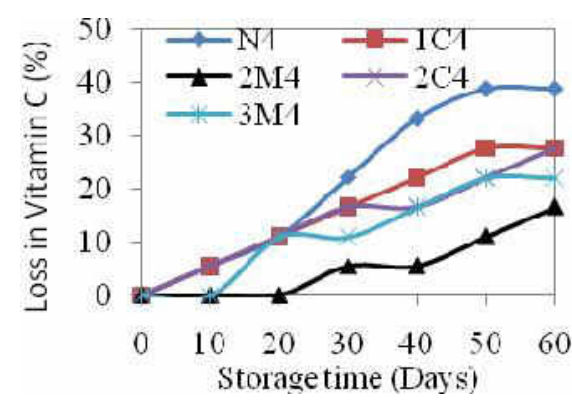

Figure 4: Vitamin $\mathrm{C}$ retention by addition of CEO and MEOs at refrigeration temperature

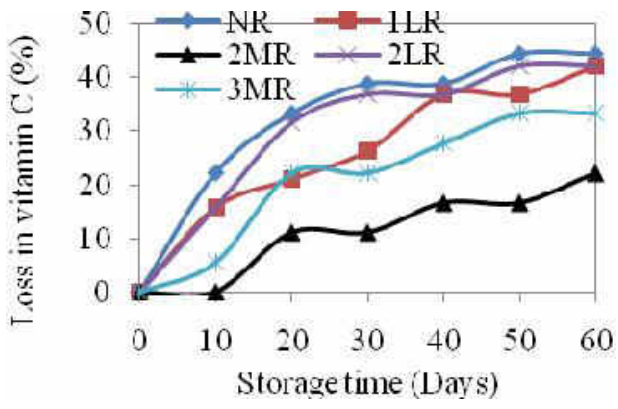

Figure 5: Vitamin $\mathrm{C}$ retention by addition of LEO and MEOs at room temperature

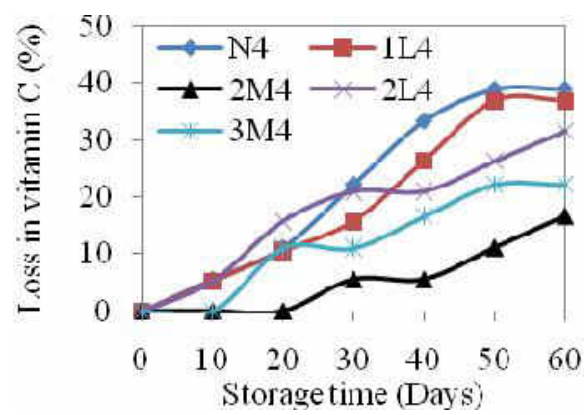

Figure 6: Vitamin $\mathrm{C}$ retention by addition of LEO and MEOs at refrigeration temperature

Figure 3 and 4 show that mixing of 500 ppm or $250 \mathrm{ppm}$ of MEOs resulted into less vitamin $\mathrm{C}$ loss than when $\mathrm{CEO}$ was used alone at a concentration of $1000 \mathrm{ppm}$ or $500 \mathrm{ppm}$. Similarly, Figure 5 and 6 show that at both room and refrigeration storage temperatures, mixing of $500 \mathrm{ppm}$ or $250 \mathrm{ppm}$ of MEOs resulted into less vitamin $C$ loss than when LEO alone was used at a concentration of $1000 \mathrm{ppm}$ or $500 \mathrm{ppm}$ respectively. This suggests that mixed EOs resulted into stronger radical- scavenging ability and thus highly reduced oxidation which can cause oxidative deterioration and nutritional losses such as the loss of ascorbic acid in foods (Ozcan and Arslan, 2011; Sacchetti et al., 2005; Singh et al., 2007). The main constituents of LEO is citrial (Masamba et al, 2003) while the major component of CEO is Eugenol (El-Baroty et al., 2010) and the other constituents are different. Since the two EOs have different composition their antioxidant, antibacterial and antifungal capabilities are due to different chemical species. Mixed addition of the two EOs led to additive/synergistic effect, leading into minimized effect on loss of vitamin C.

Generally Figure 3 - 6 show that preservation of jam using the mixed EOs at both storage temperatures resulted into less loss of vitamin $\mathrm{C}$ as compared to storage using single EO at the same total concentration. As is expected, storage at refrigeration temperature (Figure 4 and 6) resulted into lesser loss of vitamin $\mathrm{C}$ than storage at room temperature, the improved prevention of vitamin $\mathrm{C}$ loss with the addition of the EOs at room temperature is substantial when compared with control samples and is also enhanced with refrigeration (Figure 3 and 5) -. This agrees with the results of Ajibola et al. (2009). Dauthy et al. (1995) explained that vitamin $\mathrm{C}$, also known as ascorbic acid, is easily destroyed by oxidation especially at high temperatures.

Therefore, since ascorbic acid (MSDS \# 96184) is usually degraded by oxidative processes which are stimulated in the presence of light, oxygen, heat, peroxides and enzymes (Plaza et al., 2006), the results indicate that the use of mixed EOs resulted into better inactivation of enzymatic processes which decreased the rate of loss of vitamin $\mathrm{C}$ in pineapple jam. This effect was more enhanced at refrigeration temperature alarting for the idea that hurdle technology is very 


\section{Lemongrass and Cinnamon Essential Oils as Vitamin C Preservatives and Flavour}

Enhensers in Jam

important if minimum vitamin $\mathrm{C}$ loss is to be achieved.

\subsection{Effect of Mixed Essential oils (EOs) on Pineapple Jam Flavour}

Figures $7-10$ show that the flavour scores of control samples (samples without EOs) were generally lower and decreasing faster than flavour of samples containing essential oils. This justifies that both LEO and CEO have ability to enhance and maintain better flavour of jam.

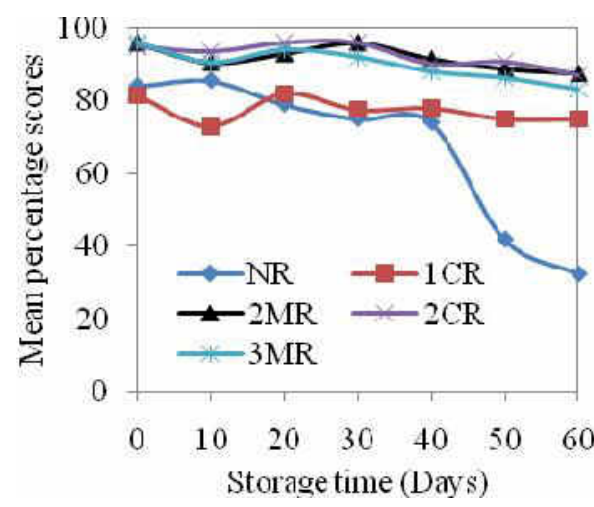

Figure 7: Flavour enhancement with CEO and MEOs in jam at room temperature

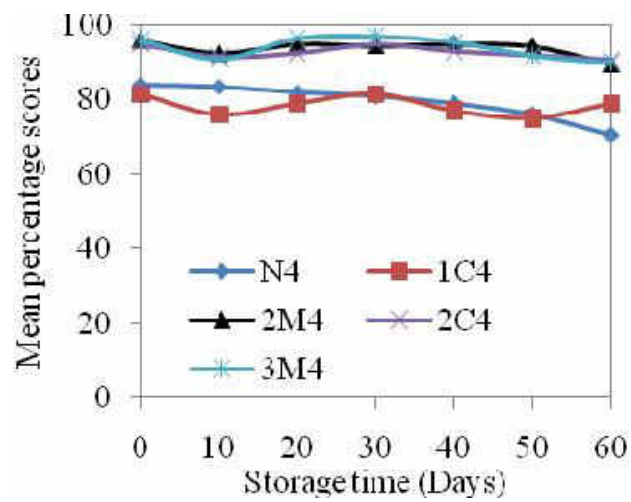

Figure 8: Flavour enhancement with $\mathrm{CEO}$ and MEOs in jam at refrigeration temperature

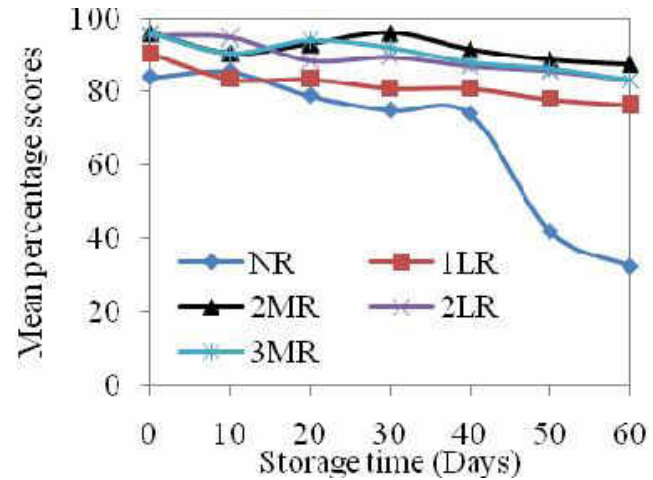

Figure 9: Flavour enhancement with LEO and MEOs in jam $\mathrm{f}$ at room temperature

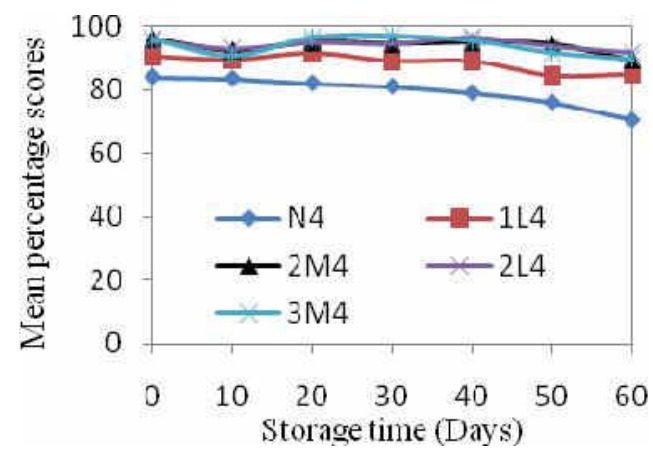

Figure 10: Flavour enhancement with LEO and MEOs in jam at refrigeration temperature

The figures also show that mixing 500 ppm of each EOs to achieve a total/combined concentration of 1000 ppm resulted into better flavour than when $1000 \mathrm{ppm}$ of either LEO or CEO were used alone. This can be explained by the fact that the mixed oil has half of pungent taste of CEO and half of the strong lemon-like flavour of LEO, hence less pungent and moderately lemon flavoured. However, mixing $250 \mathrm{ppm}$ of each EO to achieve combined concentration of $500 \mathrm{ppm}$ resulted into almost equal performance as when 500 ppm of either LEO or CEO were used alone, meaning the effect of pungent taste and lemon-like flavour in 250 and 500 ppm are too slightly diluted to be noticed. This justifies that mixing LEO and CEO helps to achieve better flavour than using single EO especially if high concentrations are to be used. 
Storage at refrigeration temperature (Figure 8 and 10) resulted into more stable flavour than room temperature storage (Figure 7 and 9) especially for samples without EO. This might be attributed to the fact that low temperature (refrigeration) hinders microbiol growth which causes off-flavour.

\section{CONCLUSION}

Both LEO and CEO have high potential to reduce loss of vitamin $\mathrm{C}$ in pineapple jam. This potential is highly manifested when the two EOs are combined. The two EOs also imparts better flavour in pineapple jam, the effect which is enhanced by combining the EOs especially if high concentrations are to be used.

Generally mixing both LEO and CEO can be exploited in maximizing their potential to reduce vitamin $\mathrm{C}$ loss in jam thereby minimizing the concentrations required to achieve preservation effect.

\section{ACKNOWLEDGEMENTS}

The researchers wish to thank the financial support of the Swedish International Development Cooperation Agency (Sida) under Food Security Programme which is one of the Sida University of Dar es Salaam (UDSM) research programmes in 2009 - 2013.

\section{REFERENCES}

Ajibola V., Babatunde O. and Suleiman S. (2009). The effect of storage method on the vitamin $\mathrm{C}$ content in some tropical fruit juices, Trends in Applied Sciences Research, 4: 79-84.

Bailey, C. (2010). Essential Oils as Natural Food Preservatives, http://suite101.com/article/essentialoils-as-natural-food-preservativesa202224. Retrieved on October 21, 2012.

Dauthy M.E., Food and Nations, A.O.o.t.U. (1995). Fruit and vegetable processing, FAO.
Davey M.W., Montagu M.V., Inzé D., Sanmartin M., Kanellis A., Smirnoff N., Benzie I.J., Strain J.J., Favell D. and Fletcher J. (2000). Plant Lascorbic acid: chemistry, function, metabolism, bioavailability and effects of processing, Journal of the Science of Food and Agriculture, 80: 825-860.

Eckerle J.R., Harvey C.D. and Chen T.S. (1984). Life cycle of canned tomato paste: Correlation between sensory and instrumental testing methods, Journal of Food Science, 49: 1188-1193.

Eke-Ejiofor J. and Owuno F. (2013). The physical-chemical and sensory properties of jackfruit (artocarpus heterophilus) jam, Int. Journal of Nutrition and Food Sci, 2(3): 149-152.

Esteve El-Baroty G.S., El-Baky H.H.A., Farag R.S. and Saleh M.A. (2010). Characterization of antioxidant and antimicrobial compounds of cinnamon and ginger essential oils, African Journal of Biochemistry Research, 4(6): 167-174

Esteve M.J. and Frígola A. (2007). Refrigerated fruit juices: quality and safety issues, Advances in Food and Nutrition Research, 52: 103-139.

Franke A.A., Custer L.J., Arakaki C. and Murphy S.P. (2004). Vitamin C and flavonoid levels of fruits and vegetables consumed in Hawaii, Journal of Food Composition and Analysis, 17: 1-35.

Material Safety Data Sheet 1(+)-Ascorbic acid MSDS\# 96184.

Özcan M.M. and Arslan, D. (2011). Antioxidant effect of essential oils of rosemary, clove and cinnamon on hazelnut and poppy oils, Food Chemistry, 129: 171-174.

Plaza L., Sánchez-Moreno C., ElezMartínez P., de Ancos B., MartínBelloso O. and Cano M.P. (2006). Effect of refrigerated storage on vitamin $\mathrm{C}$ and antioxidant activity of 
orange juice processed by highpressure or pulsed electric fields with regard to low pasteurization, European Food Research and Technology, 223: 487-493.

Rasooli I. (2007), "Food preservation-A biopreservative approach", Food, 1, 111-136.

Sacchetti G., Maietti S., Muzzoli M., Scaglianti, M., Manfredini, S., Radice, M. and Bruni, R. (2005). Comparative evaluation of 11 essential oils of different origin as functional antioxidants, antiradicals and antimicrobials in foods, Food Chemistry, 91: 621-632.

Singh G., Maurya S., Delampasona M. and Catalan C.A.N. (2007): A comparison of chemical, antioxidant and antimicrobial studies of cinnamon leaf and bark volatile oils, oleoresins and their constituents, Food and Chemical Toxicology, 45: 1650-1661.

Vidhya R. and Narain A. (2011). Formulation and Evaluation of Preserved Products Utilizing under Exploited Fruit, Wood Apple (Limonia acidissima), Am. Eurasian J. Agric. Environ. Sci, 10: 112-118.

Zheng H. and Lu H. (2011). Use of kinetic, Weibull and PLSR models to predict the retention of ascorbic acid, total phenols and antioxidant activity during storage of pasteurized pineapple juice, LWT-Food Science and Technology, 44: 1273-1281. 